\title{
Good Communication between Doctor-Patient Improves Health Outcome
}

\author{
J. Firdous and S. Hiba
}

\begin{abstract}
Communication between doctor and patient has a very important impact on health outcomes. It is basic component of any relationship especially when it is between physician and patient. It should be very strong and comprehensive. A good communication improves patient's consistence and satisfaction. It is a moral duty of a doctor that he should clear each and every query of the patient and to facilitate a patient regarding treatment and its consequences.
\end{abstract}

Keywords - Communication, Comprehensive, Consequences, Satisfaction

\section{INTRODUCTION}

"Communication- the human connection- is the key to personal and career success." (Paul J. Meyer)

Communication is an essential and integral skill for establishing physician-patient relationships and for effective functioning among health care professionals. Good communication skill in a doctor improves patient's compliance and overall satisfaction. Patient listening, empathy, and paying attention to the verbal and nonverbal components of the communication are the important ones. Studies have shown that good communication skill in a doctor improve patient's compliance and overall satisfaction. This skill can be learnt effectively during the training program for undergraduate medical students, thereby helping students to practice efficiently in patient care settings.

\section{PATIENT CENTERED COMMUNICATION}

The patient-centered clinical method commonly used for interacting with patients. Usually the patient doesn't know the medical terminologies often speak by physicians and nurses or abbreviations, symbols written on a patient's file [1]. To clarify each and every detail regarding disease, treatment or any intervention is very important. Doctorpatient communication should be perfect to get best ultimate results of patient's health [2]. The practice of good communication skills in the medical profession is integral for the development of meaningful and trustworthy relationship between the doctors and patients.

The UK's General Medical Council (GMC) emphasizes effective communication as fundamental to good medical practice. When teaching and assessing communication in the context of medical education the primary emphasis is on skills, suggesting that communication can be taught, learned and improved[3]. To pass on any information, wordings are significant, particularly if it is between specialist and patient. It's a human instinct that every patient is constantly worried about his own health, similar to what's happening in his body and when he would recoup. In this way, a good medical practitioner ought to be exceptionally cautious while advising anything to the patient [4].

\section{BENEFITS OF GOOD COMMUNICATION}

The diagnostic capability of the doctor is greatly enhanced useful in managing difficult clinical encounters and thus decreases the frustration of work stress and increase job satisfaction Patient's level of satisfaction is improved by better recognition and understanding of their ailment and disease outcome [5].

Good communication skills enable doctors to elicit information about a patient's stress and distress that is comprehensive, relevant and accurate. It has been shown that doctors, who have received training in communication skills, are more likely to detect and diagnose emotional and psychological distress and respond to patient's need appropriately than those who had not sought such training [6]. Communication is a complex phenomenon, good communication skills are more likely to make patients satisfied. Definitions vary in their emphasis on the verbal, non-verbal, content, process, informational, relational and cultural aspects of communication. Communication involves not only verbal and non-verbal interaction but also observing each other. Therefore, special skill sets are required to implement good communication. The skills include active listening, questioning, conveying information, inspiring others to speak [7]. As clinicians we are often required to communicate with patients who have very different backgrounds. Physicians have diverse ethnicity, religious beliefs and social levels. Communication with people of different backgrounds is called cross-culture communication. Cross culture communication is a part of cultural competence, which has been taught in many medical schools [8].

\section{MAINTAIN TRUST WITH PATIENTS}

Firstly, trust is an immensely important part of any relationship. Patients occasionally reveal their secrets and worries to doctors that they never have passed on, even to their family members. But if patient doesn't reveal these secrets or personal history of addictions to doctor thinking that he might disclose it before someone, it could lead to severe adverse reactions with clinician's medications. For example, alcoholics are at higher rates of pharmacological interactions. However, a doctor must stay legit with his patients and tell every positive and negative aspect of treatments he is going to give his patient, and maintain confidentiality of his patient [9]. 
$\mathrm{V}$.

\section{CLEAR THE MISCONCEPTIONS OF PATIENTS}

Patients' own perceptions regarding susceptibility to the disease have been found to be an important determinant of health seeking behavior. Without good at communication, none can convey the exact meaning of conversation. Now it has become an important part of training of medical graduates over the entire world. However, there are number of misunderstandings could be created if there is no proper counseling of the patient would be done.

"Most misunderstanding in the world could be avoided if people would simply take the time to ask, "What else could this mean?"," (Shannon L. Alder)

It's a moral obligation of doctor to explain each and every aspect of disease like its nature, course, causes, prognosis and its treatment options and treatment cost [10]. Sometimes patient has to select an options for his treatment, this needs intense focus on consequences of each option. While on the basis of experiences, a recommendation by doctor has separate significance. Usually patients are worried about their futures and want to know that how much their condition affects their lives. Due to misconceptions, patient could take wrong decisions and could go into more distress state, leading to prolonged illness. For instance, patients with type 2 diabetes have often misconception in regards to insulin treatment and this can have impact in their decision on whether or not to initiate the treatment [11].

A misbelief of patient is often due to having incomplete background knowledge of disease and its treatment plans. An observational survey was done at Los Angeles County public hospital emergency department (2015), to collect data from patients, regarding basic knowledge of appendicitis, past surgical and antibiotic history, and medical illness outcome priorities. Out of 129 subjects interviewed, $56(43 \%)$ accurately explained appendicitis, and $69(53 \%)$ picked out the treatment for appendicitis as surgery. When presented with a hypothetical acute appendicitis scenario, more than $50 \%$ subjects preferred antibiotics over surgery [12].

So, prior to provide any information in advance, try to observe what a patient already knows about his or her condition. Then, it is very essential to let patient know that many diseases could have same symptoms but their causes and treatment plans are totally different. Otherwise patient may refuse medical advice and developed high risks.

\section{PATIENT SAFETY}

Most of the time doctors are tired on their long hour duties or might be due to the tremendous number of patients in clinics, they want to avoid patients' emotional discussions and problems. This often tends to increase patients' distress. As a result of which the patient feels wavering to unveil his problems which could defer the recovery of patient [13].

The alarming numbers of patients reportedly harmed and even killed by medical errors have prompted the development of numerous trans-disciplinary, evidencebased strategies to improve patient safety. Studies have also shown that the rate of medication errors resulting in serious medical outcomes is because of lack of effective communication.

A healthy communication between patient and doctor has very important impact on patients' follow up, because first time, you have dealt with patient properly, counseled the patient in detail, it may reduce the need for admissions and readmissions in future [14-15].

\section{BARRIERS OF COMMUNICATION}

Even when the patient may know the little English, there is always a doubt whether he understands the message doctor or not. The main unfavorable impact of language barrier is that patient could not comprehend that at which time he should take meds and at what dose. Although many research papers have been described the problems doctors are facing regarding language barrier in healthcare system and its impact on patients' expectations [16-17].

A cross sectional study was done in five urban teaching hospitals' emergency departments in the Northeastern United States, to asses patient's satisfaction and willingness to return to an emergency department among non-English speakers. Overall, only 52\% of non-English speaking patients were satisfied as compared with $71 \%$ of English speaking patients $(p<.01)$. On the other hand, $14 \%$ non-English speaking patients said they would not return to the same emergency department if they had another problem requiring emergency care as compared with $9.5 \%$ of English speaking patients $(p<.05)$ [18-19].

Consequently, it has become very important that doctor who is treating the patient in clinical setup, knows patient's primary language properly, to convey the details regarding his health. Another solution that has given by many authors to overcome this language barrier problem is to provide interpreter services at emergency department and in outpatient department, as it indicated good results of understanding between doctor and patient communication [20-21].

Physicians have to deal with number of patients, some of them have high health literacy, that are much aware of their illnesses, and some are illiterate usually with less education, low incomes, and in minority . A clinician must determine the patient's degree of understanding so that he could clarify his queries in more detail. Many therapies like intra vaginal rings, dermal implants, patches, inhalers and subcutaneous depot, require special instructions to ensure proper administration [22-23]. It is very important to explain each prescription to patient in detail whether with high health literacy or with low, because identifying patients with limited health literacy can be difficult and is often undetected by doctor and can lead to negative effects on patient's health [24]. Common questions of patients and their family members are often about the diagnosis, its prognosis, effective medications, cons and pros of treatment, cost of treatment. If admission needed, how long would be the stay in the hospital? A health care professional should satisfy the patient concerning his every query [2526]. Emergency department is a place where every patient arrives in a misery state, often terrified, anxious and generally comes with blood / injection phobias. In this situation, poor behavior and harsh wordings could prompt disappointment in the patient. 
A pilot study was done for a case study in a single clinic in Malaysia. They used audio tape for recording of doctorpatient communication, in a time period of 3 months (Feb Apr 2015) and qualitative data was obtained. The objective of study was to investigate politeness strategies used between doctor and patient in a private clinic, with reference to Brown and Levinson's politeness theory. This result has shown that $45.38 \%$ of maximum politeness strategy used by the doctors and patient is the bald-onrecord type, followed by $31.09 \%$ of negative politeness strategy, $19.33 \%$ of positive politeness strategy and $19.33 \%$ with the last strategy being the off-record strategy. In this way, patients feel more comfortable with elaborating questions by doctors rather than 'Bald on Record' strategy, as it has indicated the disappointments in patients either male or female, with specialists' discussions and during follow-up visits [27].

\section{BREAKING BAD NEWS}

Any information which antagonistically and genuinely influences a person's perspective on his future is defined breaking bad news [28]. In doctor-patient interaction, a clinician's selection of vocabulary, expressions and appropriate wordings mean a lot, to clarify the exact thing. Breaking bad news is extremely unpleasant and troublesome, particularly when there is no treatment options remained. However, the conveyance of awful news by the health professionals to their patients is a key moment in the doctor-patient relationship [29]. This troublesome task requires persistence and refined relational abilities between the clinician and the patient. Breaking negative news to patient or his relatives needs professionalism, confidence, patience, and vitality.

A study had been conducted to find out how patients judge the worthiness of doctors' communication of bad news. The results showed that the quality of information and emotional strength explained more than $95 \%$ the variance in patients' acceptability judgments, while the level of badness of the news had no effect and patients expect high levels of both sympathy and information quality, regardless of how terrible the news [30].

\section{EMPATHY FOR PATIENT}

Empathy is another essential component of doctor-patient communication. Empathy as a characteristic of patientphysician communication in both general practice and clinical care is considered to be the backbone of the patientphysician relationship. Physician's empathy for the patient and patient compassion for the doctor together can improve correspondence and promote further understanding of one another's points of view [31]. Patients follow those physicians' order more, who have greater empathy for them as compare to physicians having less sympathy [32]. Clinicians, who wish to improve patients' satisfaction and consistence should initially recognize the elements of the empathic communication and afterward attempt to refine their aptitudes to more readily serve patients [33]. Another component of empathy that has an immense impact on patient's satisfaction is the doctor's tone of voice. A doctor must talk in a very polite and calm way. Most of the patients feel relaxed and unstressed when a clinician communicate nicely and calmly. A demanding and baffling patient may outrage the physician [34], but it is a duty of a doctor to control his anger and remain calm.

\section{CONCLUSION}

This review summarizes that how intense the impact of physician's verbal communication is on patients' satisfaction and health. To get best results, various strategies regarding doctor-patient communication are immensely significant. Good and effective communication can improve patient satisfaction, understanding of disease, improve compliance / adherence to drugs and ultimately improve outcome of care. Some of the barriers of effective communications are poor language, time constrain, poor listening skills and lack of empathy. However, improvement in these strategies helps the patients to recover more efficiently and gives better health outcome. 


\section{REFERENCES}

1. Rodriguez HP, Anastario MP, Frankel RM, et al. Can teaching agenda-setting skills to physicians improve clinical interaction quality? A controlled intervention. BMC Med Educ. 2008;8:3.

2. Smith RC, Dorsey AM, Lyks JS, Frankel RM. Teaching selfawareness enhances learning about patient-centered interviewing. Acad Med 1999;74:1242-1248.

3. General Medical Council. Tomorrow's Doctors: Outcomes and standards for undergraduate medical education. London; 2009.

4. McLeod ME. The caring physician: A journey in self-exploration and self-care. Am J Gastroenterol. 2003;98:2135-2138.

5. Travaline, J, Ruchinskas R, D'Alonzo G. "Patient-Physician Communication: Why and How." The Journal of the American Osteopathic Association2005; 105: 13-18.

6. Jennifer Fong Ha,Nancy Longnecker, Doctor-Patient Communication: A Review. Ochsner J. 2010;10(1): 38-43.PMID: 21603354.

7. Ranjan P, Kumari A, Chakrawarty A. How can Doctors Improve their Communication Skills? J Clin Diagn Res. 2015 Mar;9(3):JE014. doi: 10.7860/JCDR/2015/12072.5712. Epub 2015 Mar 1.

8. Fryer-Edwards K, Arnold RM, Baile W, Tulsky JA, Petracca F, Back A. Reflective teaching practices: An approach to teaching communication skills in a small-group setting. Acad Med. 2006;81:638-644

9. Duffy F. D., Gordon G.H., Whelan G., et al. Assessing competence in communication and interpersonal skills: the Kalamazoo II report. Acad Med.2004; 79((6)):495-507.

10. Brown R, Peikes D, Peterson G, Schore J, Razafindrakoto C. Six Features Of Medicare Coordinated Care Demonstration Programs That Cut Hospital Admissions Of High-Risk Patients. Health Affairs. 2012;31(6):1156-1166. doi: 10.1377/hlthaff.2012.0393

11. Brod M, Alolga SL, Meneghini L. Barriers to initiating insulin in type 2 diabetes patients: development of a new patient education tool to address myths, misconceptions and clinical realities. The PatientPatient-Centered Outcomes Research. 2014 Dec 1;7(4):437-50.

12. Kadera SP, Mower WR, Krishnadasan A, Talan DA. Patient perspectives on antibiotics for appendicitis at one hospital. Journal of Surgical Research. 2016 Apr 1;201(2):253-7.

13. Wear D, Varley JD. Rituals of verification: The role of simulation in developing and evaluating empathic communication. Patient Educ Couns. 2008;71:153-156.

14. Dobie S. Viewpoint: Reflections on a well-traveled path: Selfawareness, mindful practice, and relationship-centered care as foundations for medical education. Acad Med. 2007;82:422-427.

15. Fallon E. Chipidza, BA, Rachel S. Wallwork, BA, and Theodore A. Stern, M. Prim Care Companion CNS Disorder. 2015; 17(5): 10.4088/PCC.15f01840. PMID: 26835164

16. Hamel LM, Penner LA, Eggly S, Chapman R, Klamerus JF, Simon MS, Stanton SC, Albrecht TL. Do patients and oncologists discuss the cost of cancer treatment? An observational study of clinical interactions between African American patients and their oncologists. Journal of oncology practice. 2016 Dec 13;13(3):e249-58.

17. Kayaoğlu, M., \& Akbaş, R. An Investigation into Medical Students' English Language Needs. Participatory Educational Research,(2016); spi16(1), 63-71. doi: 10.17275/per.16.spi.1.8

18. Karliner LS, Auerbach A, Nápoles A, Schillinger D, Nickleach D, Pérez-Stable EJ et al. Language barriers and understanding of hospital discharge instructions. Medical care. 2012 Apr;50(4):283. PMID: 22411441

19. Carrasquillo O, Orav E, Brennan T, Burstin H. Impact of language barriers on patient satisfaction in an emergency department. Journal Of General Internal Medicine1999;14(2): 82-87. doi: 10.1046/j.15251497.1999.00293.x

20. Jacobs E, Shepard D, Suaya J, Stone E. Overcoming Language Barriers in Health Care: Costs and Benefits of Interpreter Services. American Journal Of Public Health 2004;94(5), 866-869. doi: 10.2105/ajph.94.5.866

21. Jacobs B, Ryan A, Henrichs K, Weiss B. Medical Interpreters in Outpatient Practice. The Annals Of Family Medicine 2018;16(1), 7076. doi: 10.1370/afm.2154. PMID: 29311179

22. Hardin, L. Counseling patients with low health literacy. American Journal of Health System Pharmacy2005;62(4): 364-365. doi: 10.1093/ajhp/62.4.0364.

23. Graham S. Do Patients Understand? The Permanente Journal 2008;12(3). doi: 10.7812/tpp/07-144. PMID: 21331214.
24. Peigne V, Chaize M, Falissard B, Kentish-Barnes N etal.Important questions asked by family members of intensive care unit patients. Critical care medicine. 2011 Jun 1;39(6):1365-71.

25. Öst, L.-G. (1992). Blood and injection phobia: Background and cognitive, physiological, and behavioral variables. Journal of Abnormal Psychology1992; 101(1): 68-74.

26. Chiew Fen $\mathrm{Ng}$, Poh Kiat $\mathrm{Ng}$ and Chiew Yean Ng. Politeness in Doctor-Patient Communications: A Pilot Study. Middle East Journal Of Scientific Research 2016;Doi: 10.5829/idosi.mejsr.2016.24.02.23026.

27. Lodhi M, Naz F, Yousaf S, Ibrar S. A Linguistic Analysis of the Politeness Strategies Used in Doctor-Patient Discourse. English Language And Literature Studies 2019;9(1): 80. doi: 10.5539/ells.v9n1p80

28. Bousquet G, Orri M, Winterman S, Brugière C, Verneuil L, RevahLevy A. Breaking Bad News in Oncology: A Metasynthesis. Journal of Clinical Oncology. 2015;33(22):2437-2443. doi: 10.1200/jco.2014.59.6759

29. Bousquet G, Orri M, Winterman S, Brugière C, Verneuil L, RevahLevy A. Breaking bad news in oncology: a metasynthesis. Journal of Clinical Oncology. 2015 Jun 29;33(22):2437-43

30. Munoz Sastre MT, Sorum PC, Mullet E. Breaking bad news: the patient's viewpoint. Health communication. 2011 Oct 1;26(7):649-55. Doi: 10.1080/10410236.2011.561919. PMID 21598151.

31. Anderson P, Wescom E, Carlos R. Difficult Doctors, Difficult Patients: Building Empathy. Journal of the American College of Radiology 2016;13(12):1590-1598. doi: 10.1016/j.jacr.2016.09.015.

32. Hojat M, Louis D, Markham F, Wender R, Rabinowitz C, Gonnella J. Physicians' Empathy and Clinical Outcomes for Diabetic Patients. Academic Medicine. 2011;86(3):359-364. doi: 10.1097/acm.0b013e3182086fe1.

33. Kim S, Kaplowitz S, Johnston M. The Effects of Physician Empathy on Patient Satisfaction and Compliance. Evaluation \& the Health Professions. 2004;27(3):237-251. doi: 10.1177/0163278704267037.

34. Levinson W. Mining for gold. J Gen Intern Med. 1993; 8: 172-3.

\section{Biography}

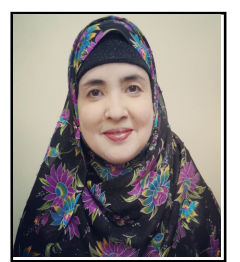

Dr FIRDOUS JAHAN

Associate Professor/ Head of the Department Family Medicine

College of Medicine and Health Sciences ,National University, Sohar

Oman

Email: firdousjahan@nu.edu.com

MBBS from Sindh University securing first class 1st position in final professional MBBS examination. Done MCPS and FCPS from College of Physician and Surgeon Pakistan. I have been associated with Aga Khan University Hospital Karachi Pakistan (AKUH) as faculty since 2002 till 2011 and have been contributing extensively to education, research and service and served in academic and administrative position. Joined College of Medicine (Oman medical college) in 2011 till date working as associate professor/ chair family medicine.

Dedicated and knowledgeable educator with more than 25 years of service in health care . Long history of experience as physician. Commitment to delivering effective instructional and theory background and helping develop better clinical experiences for students. Focused on preparing each candidate to be an effective health care provider for the future.

At institutional level I have been the member of several important committees concerning research and curriculum. Currently chairing Research and Ethical Committee of medical college. Research special interest is in medical education, non-communicable diseases and public health issues. Published research articles in peer reviewed journals. Other scholarly activities include abstract presentation in national and international conferences.

Demonstrated communication skills when delivering lectures to students, reviewing student progress individually, or communicating via email to program heads. Strong background and knowledge of medicine, drugs, diagnostic tools, and medical terminology and management skills in health care. Created an instructional material for classroom study and preparation 
for clinical experiences for students. Supervise students in their clinical rotation in a health care facility. Assess student work in the classroom by reviewing test results, evaluating laboratory work, and reading journals. Lead a team of undergraduate student in clinical rotations in the primary health care system. Advised student nurses of specific goals to work on to improve performance in the program and reach their goals.

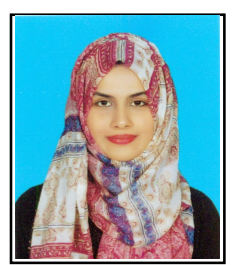

DR HIBA SIDDIQUI

Resident Medical Officer,

Dr. Ziauddin Hospital, Karachi

Pakistan

Email: dr.hibasiddiqui@yahoo.com

Did MBBS from Karachi Medical And Dental College in 2016. Completed medical training from Abbasi Shaheed Hospital in 2017. Worked in Mamji Hospital Karachi as resident medical offier, in medicine department in 2018. There, I did research work in paedriatic ward and emergency regarding Antimicrobial Drug resistance in Childhood Typhoid Fever, published in Asian Journal of Infectious Diseases in March 2019.

Currently working in Dr. Ziauddin Hospital Karachi as a resident medical officer in Oncology department, managing and counseling the cancer patients regarding their health. 